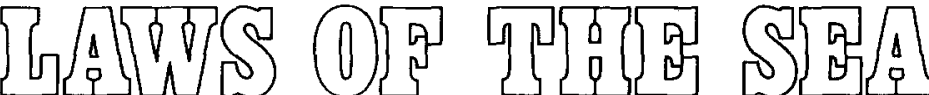

\section{Land-Based Discharges of Marine Debris: From Local to Global Regulation}

ANDRE NOLLKAEMPER

Faculty of Law, Erasmus University Rotterdam,

PO Box 17383000 DR, Rotterdam, The Netherlands

This article outlines the major regulatory requirements involved in the control of land-based discharges of marine debris, and reviews the main developments in the process towards more appropriate international controls of such discharges.

Marine debris poses a continuing threat to marine ecosystems. Most visibly, it has resulted in entanglement of marine wildlife. Debris washing up on beaches may also have considerable economic impacts, such as lost tourism and recreation potential. Most of the concern has focused on debris discharged from vessels. However, there is now ample evidence that land-based discharges are a major source of marine debris. Much of the existing knowledge on these issues was presented at the Third International Conference on Marine Debris, May 1994, Miami.

Absence of sewage treatment installations, combined sewer outflows, storm water discharges, run-off landfills sited nearby rivers and in coastal areas, absence of waste services or landfills in rural ares, and beach littering all contribute to debris ending up on beaches or in oceans.

Regulation of such land-based discharges has been underdeveloped. In many states, local and national rules are anywhere between absent and inadequate. The argument that local and national efforts should be backed up by international regulations is well established. In summary, such regulations serve to induce states to install sewage treatment works, to prevent industrial discharges of plastics and to undertake other preventive action where they are otherwise unwilling, or incapable of doing so; to prevent economic disruptions that may be caused by unilateral actions such as mandatory packaging controls; to prevent transboundary pollution of marine debris; and to offer economics of scale in such fields as public awareness and education, and development and application of clean production processes.

Yet, in marked contrast to the regime for sea-based pollution (Annex V to MARPOL 73/78), international rules to induce appropriate national and local policies on land-based discharges lead a marginal existence. For one thing, too few states have been willing or able to participate in regional instruments. Some 20 years after the first regional instrument, at present only several regions (the North East Atlantic, the Mediterranean
Sea, the Baltic Sea, the Black Sea and the Arctic) are covered by more or less operational programmes for land-based pollution, whereas programmes for the South East Pacific and the Persian Gulf are as yet dormant (Nollkemper, 1992). Equally significant, existing programmes have been inadequate. They have not addressed the full range of sources of marine debris; they have treated land-based pollution too much as an isolated problem, as if unrelated to waste generation; and have provided insufficient inducements by way of information exchange, technical co-operation and financial assistance to move marine debris higher on the agenda of, in particular, developing states. Each of these problems will be elaborated below.

The bleak prospects for adequate regional solutions rightly has set in motion a global process. Responding to the imperatives set forth in Agenda 21 (adopted at the 1992 UNCED), a global programme of action for land-based sources of marine pollution is now being prepared, scheduled for adoption in November 1995 in Washington, DC, with prepatory meetings in Nairobi, December 1993 and Montreal, June 1994 and Reykjavik, March 1995. This programme should constitute a commanding global strategy to re-activate existing regional instruments and induce the introduction of such instruments in regions where landbased pollution is an as yet unregulated source of disturbance of marine ecosystems. Marine debris, having been identified in Agenda 21 as one of the main forms of land-based pollution, will be one of the focal points sources of the global programme of action.

The following three sections will indicate the main issues to be addressed in future regional agreements, and to be supported and guided by the global programme of action.

\section{Coverage of All Land-based Sources of Marine Debris}

Existing regional regulations have not focused on marine debris as a priority issue. They have mostly confined themselves to two sources of debris: point sources and sewage installations.

Point sources have justifiably been covered by regional instruments. There is evidence of industrial discharges of debris from point discharges to surface waters (Bauer \& Iudicello 1990, at 79). Agreements for the North East Atlantic, Baltic Sea and the Mediterranean Sea have included floatables in the black list, and thereby obliged states to eliminate discharges of floatables. However, this has largely remained a symbolic obligation. Whereas specific targets have been developed for other black list substances, such as mercury and cadmium, none have been developed for floatables.

Sewage treatment has elicited more regulatory activity (more caused by concern over nutrient inputs 
than over solid wastes). Several fora have set targets for sewage treatment, for instance for the Mediterranean Sea (in 1991 the Contracting Parties to the Barcelona Convention adopted a plan for the collection, treatment and disposal of sewage for each Mediterranean coastal city with a population of over 10000 inhabitants); the Black Sea (in the 1993 Ministerial Declaration the coastal states agreed to construct sewage treatment plants as a matter of urgency), the North Sea (as recently confirmed in the Statement of Conclusions of the Intermediate Ministerial Meeting, 7-8 December 1993, Copenhagen), the North East Atlantic, the European Union and the United States and Mexico. The degree to which these agreements have been able to reduce discharges of untreated sewage differs. For instance, in the Mediterranean Sea and the Black Sea such discharges are still abundant. A key barrier to more effective programmes is the lack of adequate funding.

Next to the often unsuccessful programmes concerning point discharges and sewage treatment, other sources of marine debris have rarely or not been addressed.

Storm water run-off from urban areas, construction areas and landfills is a major land-based source of debris. The USA Environmental Protection Agency concluded that storm water run-off is one of the most significant remaining threats to the quality of surface water in the United States (20 BNA Env't Rep., 1992, p. 2569). A 1990 Recommendation of the Helsinki Commission on Reduction of Discharges from Urban Areas by Proper Management of Stormwater is an isolated and rare effort to induce national controls for this source.

Where stormwater and sanitary sewage systems are combined, in wet weather, the capacity of sewage treatment facilities can be overwhelmed resulting in untreated discharges. In the USA, overflow mechanisms, built into such systems to divert the wastewater and stormwater to avoid overloading the sewer system, are one of the major land-based sources of plastics (20 BNA Env't Rep., 1990, p. 1842). This problem has drawn little international attention.

Run-off from landfills sited nearby rivers or in coastal areas may end up in the marine environment. In the USA, many estuaries have been affected by thrash as a result of solid waste sitings near estuaries (23 BNA Env't Rep., 1992, p. 1428). There is a clear need for regulations ensuring that solid waste facilities do not result in a washout by floods so as to pose a hazard to the aquatic environment.

Absence of waste services in urban and rural areas near coastal areas is a direct threat to the marine ecosystem. Agenda 21 notes the unnerving figures that by the end of the century, an estimated half of the urban population in developing countries will be without adequate waste disposal services. No international instruments for land-based pollution have concerned themselves with this issue.

International instruments have also not concerned themselves with beach littering. This is a significant source of debris (20 BNA Env't Rep., 1990, p. 1842). It is true that this is an unrewarding object of legal controls; littering by individuals spending their day on the beach or along river-shores, or who dump thrash from bridges into rivers resists effective control by any law, and enforcement is bound to be haphazard and accidental. But there is a clear need for programmes focusing on educating and informing the public about consequences of littering.

Future instruments on land-based pollution should, depending on the nature of the debris problem in a specific region, to a greater extent cover the full scope of land-based sources of debris and extend themselves to sewage and waste water treatment, waste services, design, siting and operation of landfills, storm drains, and other measures for managing wastes.

Major support for such a broadened scope can be provided by the global programme of action. At the moment of writing, the contents of the global programme of action as regards land-based discharges of marine debris has yet to be developed. In part, it can build on the targets contained in Agenda 21 which: (i) contains targets for ensuring that sewage, waste water and solid wastes are treated and disposed of in conformity with national or international environmental and health quality guidelines; (ii) requires improvement of coastal human settlements, inter alia in treatment and disposal of solid wastes; (iii) contains recommendations for public awareness and education; and (iv) sets objectives for extending waste service coverage in urban areas. The global programme of action needs to build on, extend and specify these targets.

\section{Integration with Prevention of Waste Generation}

Existing instruments have been drafted to deal, and indeed have dealt with, land-based pollution as an isolated problem, rather than as an integral part of larger problems of waste generation and management. It is now clear that this is an ineffectual approach. A strict separation between land-based pollution and overall waste management and reduction policies can no longer be deemed acceptable.

Land-based marine pollution, including pollution from upland discharges of marine debris, are not to be considered an isolated set of problems. Rather, they are an integral part of sound environmental management and pollution control for every waste management activity. The very policies that reduce generation of solid wastes will prevent them from entering the environment. For instance, it has plausibly been suggested that there are direct links betwen recycling programmes and the amount of debris washing up on beaches; relatively small amounts of plastic found on Scandinavian beaches have been said to be due to 'progressive re-use and recycling of plastic in Scandinavia' (16 BNA Int. Env't Rep., 1993, p. 655).

Future regional programmes should take into account these inter-relationships. Either their scope should be broadened, and make recycling and source reduction subject to their regulatory programmes, or they should provide for adequate linkages with re- 
cycling and waste generation programmes developed in other international fora.

The main regulatory options for recycling and source control are well established and are being applied to differing degrees (Nollkaemper, 1994). For recycling, they include targets for recycling to be achieved by manufacturers and in municipal waste recycling; recycling contents mandates on packaging; taxes or fees to encourage recycling, for instance on products made with virgin materials or on products that do not meet recycling standards; incentives for development of new technologies furthering recycling; and creating markets.

Among the options for source control are: bans on products (such as six-packs); product standards, such as for non-degradable ring-carriers; standards requiring the packaging industry to reduce the amount and control the types of packaging; fees or taxes on, for example, litter generating products, packaging, or waste disposal to remedy the distorted incentives which do not take into account true disposal costs, and thus distort consumer and manufacturing decision-making; and incentives for development of clean technology.

Here, too, the global programme of action can provide meaningful directon. One of the key features of Agenda 21 is its linkage between different sectoral issues such as land-based marine pollution on the one hand, and general issues such as waste generation and management on the other. While not explicitly applied to marine debris, recycling and source control feature prominently in Agenda 21. It calls for efficient waste reuse and recycling; public eduction and awareness programmes to promote use of recycled products; funding for pilot programmes for recycling; identification of markets for recycled products; stabilization or reduction of the production of wastes over an agreed time-frame; and reduction of packaging materials.

Further development of targeted and costed programmes for these issues will be decisive for the success of efforts to reduce marine debris problems. It is of concern that, with respect to recycling and prevention of waste generation, no follow-up process has been set in motion comparable to the development of the global programme of action for land-based pollution. It will be essential in the global programme of action to provide for adequate linkages with international programmes simulating national recycling and waste reduction.

\section{Funding and Technological Co-operation}

Marine debris is a major actual and potential problem outside the developed world. With the dispersion of western products and packaging throughout the world and a growing lack of capacity for waste disposal, these problems can be expected to magnify in the years to come. Many states are economically or technologically unable, or lack the information and expertise, to implement policies to reduce generation of waste and improve disposal of waste. Where resources are scarce, prevention of marine debris will not emerge as a priority.

One of the main objectives of the global programme of action is to provide for reinforced technological co-operation, exchange of information and transfer of financial resources. It is to build on the universally accepted linkages set forth in Agenda 21 between substantive requirements for prevention of marine pollution and financial and technical co-operation, and ensure that requirements are realistic and achievable.

Agenda 21 indicated several of the elements on which the global programme of action should focus. For instance, as regards sewage, the programme could set targets for coastal populations to have properly managed sewage, and supplement these by strategies to achieve that objective including mechanisms for inventory and transfer of low-cost systems for management and treatment of sewage; and mechanisms for financial support, such as an international fund for planning, design and construction of sewage treatment technologies. As regards waste minimization, key elements of an effective strategy are transfer of technology to support waste recycling and technology and dissemination of waste minimization technologies and procedures, including facilitation of transfer of waste reduction technologies to industry in developing countries.

Significantly, the development of substantive strategies for waste disposal and prevention of debris should help co-ordinate and focus the activities of funding institutions. In recent years there has been an increasing willingness of donors to support relevant projects, such as the support by the Global Environmental Facility for waste water treatment in the Black Sea; the funding by the European Union of Black Sea protection programmes; European Investment Bank lendings for solid waste disposal in the European Union; funding of reduction of sewage problems and solid waste disposal in Rio de Janeiro by the InterAmerican Development Bank and the Japanese Overseas Economic Co-operation Fund; and investments in Mexican waste water treatment facilities by the International Finance Corporation.

Agreement on common objectives and strategies for reducing marine debris could enhance the readiness of donors to support national and local programmes. At the time, it could help to focus financial support on internationally agreed priority issues, in much the same manner as the Global Environmental Facility already focuses its financial support on the implementation of internationally agreed rules.

\section{Concluding Observations}

There is a clear momentum for development of international controls for land-based sources of marine pollution. In many regions treaties or programmes have been developed in recent years or are in the process of development. The global programme of action will support and guide these regional programmes.

The increasing knowledge that has become available on the sources and effects of marine debris makes this an excellent opportunity to develop adequate international regulatory programmes for the prevention of land-based marine debris. Full coverage of sources of marine debris, integration of waste disposal issues with 
prevention of waste generation and development of adequate strategies for funding and technological cooperation are prime objectives for such programmes. Elaboration of these objectives at global and regional levels should help to induce more integrated, targeted and effective regional, national and local programmes for the prevention of marine debris.

Baur, D. C. \& Iudicello, S. (1990). Stemming the tide of marine debris pollution: putting domestic and international control authorities to work. Ecology Law Quarterly $17,71$.

Nollkaemper, A. (1992). Marine pollution from land-based sources: towards global approach. Mar. Pollut. Bull. 24, 8.
Nollkaemper, A. (1994). Legal regulation of upland discharges of marine debris: from local to global controls and back. Proc. Third Int. Conf. on Mar. Debris, May 1994, Miami (forthcoming).

\section{Bibliography}

Bean, M. J. (1986). Legal strategies for reducing persistent plastics in the marine environment. Paper presented at the Sixth International Ocean Disposal Symposium, p. 8, April 1986.

Kindt, J. W. (1984). Solid wastes and marine pollution. Catholic Univ. Law Rev. 34, 37.

Menell, P. S. (1990). Beyond the throwaway society: an incentive approach to regulating municipal solid waste. Ecol. Law Quarterly 17,655 .

Recent Developments: Federal Regulation of Solid Waste Reduction and Recycling, Harvard J. Legislat. 29, 251. 